\title{
Salivary Lysozyme: Its Relation to Angular Stomatitis in Ariboflavinosis
}

Part II.

\section{Lytic Action of Lysozyme upon Micrococcus Lysodeikticus Cultured with or without Riboflavin}

By

\section{Hiromichi Oyake}

From the Department of Pediatrics, Faculty of Medicine, Hirosaki University, Hirosaki; Director: Prof. Ts. Arakawa

(Received for publication, June 28, 1961)

As has already been shown by Fleming, ${ }^{1}$ micrococcus lysodeikticus succumbs easily to lytic action of lysozyme.

A low activity of salivary lysozyme in boys of slight to moderate ariboflavinosis was identified in my previous investigation. ${ }^{21}$ In the present paper I desire to show an influence of riboflavin added to culture media of micrococcus lysodeikticus upon susceptibility of the microorganism to the lytic action of lysozyme.

\section{MATERIALS AND METHODS}

Composition of culture media for micrococcus lysodeikticus

Four kinds of media were used (Media I-IV). With exception of riboflavin, the composition of Media II-IV was the same as that of Medium I.

Medium I : Agar was added in concentration of $2.5 \%$ to Kuwahara's liquid medium ${ }^{3)}$ for staphylococcus. No riboflavin was contained in it (cf. Table I).

Medium II : Riboflavin was added in a concentration of $1 \mathrm{mg}$ per $100 \mathrm{cc}$ of Medium I.

Medium III : Riboflavin was added in a concentration of $2 \mathrm{mg}$ per $100 \mathrm{cc}$ of Medium I.

Medium IV : Riboflavin was added in a concentration of $3 \mathrm{mg}$ per $100 \mathrm{cc}$ of Medium I.

Successive transplantation of micrococcus lysodeikticus upon each of Media $I-I V$

小宅 弘道 
TABLE I. Composition of Medium I (or Medium Kuwahara).

\begin{tabular}{ll|lc}
\hline Tryptophane & $0.01 \mathrm{~g}$ & $\mathrm{NaCl}$ & $5.0 \mathrm{~g}$ \\
Cystine & $0.0 \mathrm{lg}$ & $\mathrm{MgSO}_{4} \cdot 7 \mathrm{H}_{2} \mathrm{O}$ & $0.2 \mathrm{~g}$ \\
Casein hydrolysate & $1.0 \mathrm{~g}$ & $\mathrm{KH}_{2} \mathrm{PO}_{4}$ & $0.35 \mathrm{~g}$ \\
Glucose & $1.0 \mathrm{~g}$ & $\mathrm{Na}_{2} \mathrm{HPO}_{4} \cdot 12 \mathrm{H}_{2} \mathrm{O}$ & $2.5 \mathrm{~g}$ \\
Nicotinamide & $1.23 \mathrm{mg}$ & $\mathrm{Agar}^{25.0 \mathrm{~g}}$ \\
Thiamine & $0.033 \mathrm{mg}$ & Distilled water up to $1000 \mathrm{cc}$ \\
& & \multicolumn{2}{|c}{$(\mathrm{pH} 7.2)$}
\end{tabular}

Micrococcus lysodeikticus cultured with the ordinary agar plate was transplanted on a slant agar of Medium I, and cultured on it for 48 hours at $37^{\circ} \mathrm{C}$ -the first generation of the micrococcus on Medium I. The microorganism thus cultured was transplanted upon another slant agar of Medium I and cultured for 48 hours at $37^{\circ} \mathrm{C}$ - the second generation on Medium I. In such a way the transplantation and culture were carried out until the 20th generation on Medium I was obtained.

Such transplantation and culture as were carried out in the case of Medium I were simultaneously performed in the cases of Media II, III and IV. The generations of from the first to 20th on each of Media I-IV were thus obtained.

Estimation of susceptibility of micrococcus lysodeikticus to lytic action of lysozyme

Principle of estimation: If concentration of lysozyme and that of micrococcus lysodeikticus to be tested are kept being fixed, dissolution of the microorganisms will take place in large or small extent corresponding to high or low susceptibility of the microorganisms to lytic action of the lysozyme respectively.

For the purpose of a numerical expression of susceptibility of the microorganism to lysozyme, I adovocated the term "percentage of dissolved microorganisms", that meant a percentage of an amount of the dissolved microorganisms as compared with that of the microorganisms which existed prior to being subjected to lytic action of the lysozyme.

Details of procedure

1) "Micrococcus suspension of original concentration": A micrococcus suspension in $\mathrm{M} / 15$ phosphate buffer of $\mathrm{pH} 6.8$ was so prepared as to get a concentration of 50 degrees of optical density at $640 \mathrm{~m} \mu$ by Leitz-photometer.

2) $4 \mathrm{mg} \%$ solution of lysozyme (Worthington Biochem. Co. U.S.A.)

3) Technique

$5.0 \mathrm{cc}$ of "the micrococcus suspension of original concentration" were put into each of two test tubes (tube $\mathrm{T}$ and tube $\mathrm{C}$ ), then $0.5 \mathrm{cc}$ of the lysozyme solution was added to tube $T$, while $0.5 \mathrm{cc}$ of the phosphate buffer was added to 
tube C. The content of each was mixed well and kept at $37^{\circ} \mathrm{C}$ for 12 hours. After incubation, optical density of the content of each of the tubes was read at $640 \mathrm{~m} \mu$ by Leitz-photometer. Suppose optical densities: $O_{T}$ and $O_{C}$ were found in the cases of tubes $\mathrm{T}$ and $\mathrm{C}$ respectively, then "the percentage of the dissolved micrococcus" could be calculated according to the following formula: $\left(1-\mathrm{O}_{T} / \mathrm{O}_{C}\right) \times 100 \%$.

\section{RESULTS AND DISCUSSION}

In the above experiments, "the percentage of the dissolved micrococcus" was the same in the first generation in all the cases of Media I, II, III and IV,

TABLE II. Percentage of dissolved microorganism at Various Generations on Media I-IV.

\begin{tabular}{l|ccccc}
\hline Generation & \multicolumn{5}{c}{ Percentage of dissolved microorganism } \\
\cline { 2 - 6 } & 1st & 5 th & 10 th & 15 th & 20th \\
\hline Media & 39 & 38 & 39 & 39 & 40 \\
Medium I & 36 & 31 & 26 & 25 & 25 \\
Medium III & 38 & 29 & 23 & 21 & 21 \\
Medium IV & 36 & 30 & 21 & 19 & 19
\end{tabular}
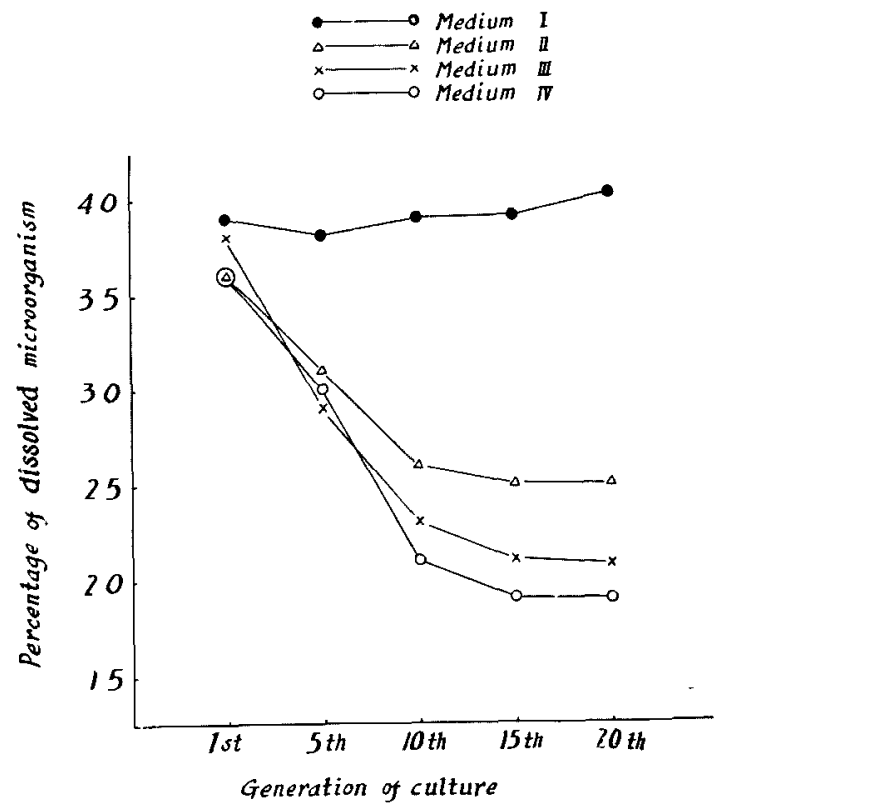

Fig. 1. Percentage of dissolved microorganism at various generations on Media I IV. 
while in and from the 5th generation downwards it began to decrease remarkably in the cases of Media II, III and IV, then a tendency of the decrease was somewhat different according to the different media, the most conspicuous being Medium IV, then Medium III, the least conspicuous being Medium II. From these results it was highly probable that micrococcus lysodeikticus became more resistant against lytic action of lysozyme when it was maintained on riboflavin containing media as compared with the case in which it was cultured with riboflavin-free medium, and that the larger the riboflavin content in the media, the more resistant became the microorganism against lytic action of lysozyme.

Since the first report of Fleming ${ }^{1)}$ concerning a lytic action of lysozyme upon micrococcus lysodeikticus, several authors investigated the mechanism through which the microorganism was dissolved by lysozyme. According to Epistain et $a .^{4)}$ and Boasson ${ }^{51}$ a certain alteration of polysaccharides of cell membrane of micrococcus lysodeikticus was brought about by lysozyme with the final dissolution of the microorganism.

Matsunaga's report ${ }^{6)}$ was, as far as I know, only one dealing with the susceptibility of micrococcus lysodeikticus from view point of composition of culture media of the microorganism. Matsunaga ${ }^{6}$ ) used the Kuwahara's medium $^{3}$ ) and found that the susceptibility of the microorganism was increased when the medium was deprived of thiamine or nicotinamide. But in his report no discription was found concerning riboflavin as an ingredient of culture media for micrococcus lysodeikticus.

\section{REMARKS}

Susceptibility of epithelial cells from lips of boys with ariboflavinosis to lytic action of lysozyme will be reported in Part III.

\section{CONCLUSIONS}

Riboflavin added to culture media of micrococcus lysodeikticus reduced the susceptibility of the microorganism to lytic action of lysozyme.

\section{References}

1) Fleming, A., Proc. Soc. Biol. Med., 1922, 93, 306.

2) Oyake, H., Tohoku J. Exp. Med., 1961, 75, 190.

3) Kuwahara, S., Yakugaku (Jap.), 1949, 3, 48.

4) Epistain, L. A. \& Chain, E., Brit. J. Exp. Path., 1940, 21, 339.

5) Boasson, E. H., J. Immunol., 1938, 34, 281.

6) Matsunaga, F. Nagasaki Igaku (Jap.), 1956, 31, 586. 